REPORT ON THE BUSINESS MEETING, FRIDAY JUNE 232000

\title{
Conferencia
}

Wim Mook, the organizer of the Groningen conference discussed an idea that was first brought up at the Tucson conference in 1991. The idea is that it is not efficient to hold different conferences on significantly overlapping research areas, e.g. ${ }^{14} \mathrm{C}$, AMS, and Archaeology, and that it could be a good idea for these conference to "join forces" and coordinate the timing of future conferences. Following a general discussion it was decided not to change the present situation. The result of a postconference email ballot by Wim Mook and Walter Kutschera was inconclusive.

\section{A New Journal}

Ganna Zaitseva brought to the attention of the participants a new journal, Radiocarbon and Archaeology, published by the Institute for the History of Material Culture in the Russian Academy of Science, St Petersburg. Further information is available from ganna@mail.wplus.net.

\section{Next ${ }^{14} \mathrm{C}$ Conference}

There was one offer-to hold the 18th International Radiocarbon Conference in New Zealand. It was put forward by Rodger Sparks of the Rafter Radiocarbon Laboratory was accepted unanimousely.

\section{Applause}

A well deserved applause was extended to Target Tours who very ably organized the practical aspects of the conference. 